\title{
AS CONTRIBUIÇÕES DOS CONHECIMENTOS TRADICIONAIS INDÍGENAS PARA A EDUCAÇÃO AMBIENTAL BRASILEIRA
}

\author{
THE CONTRIBUTIONS OF TRADITIONAL KNOWLEDGE INDIGENOUS TO BRAZILIAN \\ ENVIRONMENTAL EDUCATION
}

\author{
Elisangela Castedo Maria do Nascimento \\ Heitor Queiroz de Medeiros ${ }^{2}$
}

Resumo: Este artigo é um ensaio teórico sobre a Educação Ambiental na pós-colonialidade articulada com saberes ancestrais indígenas e conceito de Ecologia de Saberes. O objetivo desse artigo foi compreender os tropeços da Ciência Moderna em relação ao meio ambiente e a cultura indígena assim como fazer o diálogo entre autores Pós-Coloniais e dos Estudos Culturais que podem contribuir para a construção de uma Educação Ambiental que valorize os conhecimentos das sociedades detentoras de conhecimentos tradicionais. Como metodologia utilizamos o levantamento bibliográfico que foi utilizado na fundamentação teórica contribuindo para as reflexões acerca da modernidade e a expropriação ambiental. Com o desenvolvimento da ciência moderna constrói-se a ideia de crescimento e desenvolvimento. Acreditava-se na razão e no poder da ciência como resposta para todos os problemas da humanidade. A ciência teve seu apogeu no século XIX e início do século XX, com muitos avanços e sua aplicação prática na vida diária das pessoas por meio da tecnologia, mas é também no século XX que as consequências negativas apareceram afetando a qualidade de vida do ser humano, sendo chamados de problemas socioambientais, havendo necessidade de reavaliar as crenças da razão.

Palavras chave: Ciência Moderna. Natureza. Saberes Ancestrais Indígenas.
Summary: This article is a theoretical essay on Environmental Education in postcoloniality articulated with indigenous ancestral knowledge and the concept of Ecology of Knowledge. The objective of this article was to understand the stumbling blocks of Modern Science in relation to the environment and the indigenous culture as well as to make the dialogue between Postcolonial authors and Cultural Studies that can contribute to the construction of an Environmental Education that values the knowledge of societies holders of traditional knowledge. As a methodology we used the bibliographic survey that was used in the theoretical foundation contributing to the reflections about modernity and environmental expropriation. With the development of modern science the idea of growth and development is built. It was believed in the reason and power of science as an answer to all the problems of humanity. Science had its heyday in the nineteenth and early twentieth centuries, with many advances and their practical application in people's daily lives through technology, but it is also in the twentieth century that the negative consequences appeared affecting the quality of life of the human being, being called socioenvironmental problems, and there is a need to reevaluate the beliefs of reason.

Keywords: Modern science. Nature. indigenous ancestral knowledge.

\section{INTRODUÇÃO}

\footnotetext{
${ }^{1}$ Doutoranda em Educação na Universidade Católica Dom Bosco (UCDB). E-mail: <ecmcursino@yahoo.com.br>

${ }^{2}$ Professor na Universidade Católica Dom Bosco (UCDB) estando credenciado no Programa de Pós-Graduação em Educação. Email:<4668@ucdb.br>
} 
Neste artigo buscamos respostas para os questionamentos presente nas teorias Pós-Coloniais e Estudos Culturais (EC) no diálogo com os pressupostos da Educação Ambiental (EA), na tentativa de apontar, resgatar e valorizar os saberes tradicionais indígenas como significativos para a conservação do meio ambiente assim como na formação de sociedades sustentáveis, visto que a modernidade produziu uma sociedade consumista que valoriza e coloca o "ter" acima do "ser".

Desde meados do século XX se tem estudado os impactos antrópicos sobre o meio ambiente e ninguém pode alegar desconhecimento da importância dos seres vivos para a teia alimentar, dos vegetais para o clima do planeta e que a vida em geral tem sido ameaçada pelo estilo de vida do ser humano baseado na lógica capitalista do consumo.

Assim, buscamos compreender os tropeços da ciência moderna em relação ao meio ambiente, com as consequências da utilização irracional dos recursos ambientais visando o lucro a qualquer preço, sabendo que esse modelo tem como consequência imediata os problemas socioambientais resultantes da perda de vínculo do homem com a natureza no decorrer da história moderna.

Hoje os estudiosos da EA buscam também nos saberes tradicionais das comunidades indígenas, alternativas e soluções para o enfrentamento da crise socioambiental em que vivemos e que coloca em xeque a manutenção de todas as formas de vida do planeta em função dos impactos ambientais consequentes da lógica irracional da modernidade com sua forma de exploração da natureza, contrariando o que era disseminado no projeto moderno que colocava os saberes das comunidades autóctones como menores, sem valor. A respeito dessa desvalorização, nos últimos tempos há uma grande preocupação com os rumos da política em relação às questões ambientais e indígenas no Brasil.

Dessa forma, justificamos a relevância desse artigo, como uma tentativa de visibilizar a importância dos conhecimentos tradicionais indígenas para conservação da vida humana e de outras espécies, sobre a terra, baseada num estilo de vida que é sustentável pois estruturada a partir de uma relação de respeito com a diversidade de formas de vida presente no planeta, ou seja, com respeito toda forma de ser.

\section{Metodologia}

Embasamos essa pesquisa nos estudos pós-críticos que utilizam procedimentos metodológicos para produção de conhecimento que objetivam descontruir discursos e possibilitar a transformação educacional e social (MEYER e PARAISO, 2012). Optamos por realizar uma pesquisa qualitativa e bibliográfica na busca da compreensão da relação ambiental do indígena com a natureza, visto que, esse tipo de pesquisa é reconhecido entre as ciências sociais, como tendo "um nível de realidade que não pode ou não deveria ser quantificado. Ou seja, ela trabalha com o universo de significados, dos motivos, das crenças, dos valores e das atitudes" (DESLANDES, GOMES e MINAYO, 2009, p. 21).

Portanto o objetivo desse artigo foi buscar compreender os tropeços da ciência moderna em relação ao meio ambiente e a cultura indígena assim como fazer o diálogo entre autores pós-coloniais e dos estudos culturais que podem contribuir para a construção de uma Educação Ambiental que valorize os conhecimentos das sociedades detentoras de conhecimentos tradicionais. Para alcançar esse objetivo, fundamentamos a pesquisa nos autores e seus conceitos, tais quais: pós-coloniais, (LANDER, 2005) e a "Ruptura ontológica", (ESCOBAR, 2005) com o "Lugar", (SANTOS 2007, 2008) com a "Ecologia de Saberes"; Estudos culturais, (HALL, 2003) com "Hibridismo" e "Ressignificação"; e (TRISTÃO, 2004, 2014, 2016) com a "Educação Ambiental", entre outros. As categorias analisadas foram: saberes tradicionais, cultura e educação ambiental.

\section{FUNDAMENTAÇÃO TEÓRICA}

\section{Século XV - Marca o Início de um Mundo Moderno}

No passado, nas sociedades gregas a vida do homem era regida pela mitologia e rituais, a natureza e seus fenômenos eram explicados por essa forte conexão com o mundo espiritual (SANTOS, 2013). Havia vários Deuses, um para cada fenômeno natural da Terra, a explicação da natureza estava no divino. Zeus (raios e trovões), Poseidon (mar), Hades (mundo inferior), Ártemis (Lua, caça e pureza), Apolo (Sol), Dionísio (vinho e festas), Afrodite (amor e casamento) entre muitos outros Deuses. "Nas diversas divindades e seus poderes, havia um sentido de Cosmos, sendo o mundo natural e o mundo humano 
domínios unificados no universo arcaico grego" (SANTOS, 2013, p. 3). Para qualquer ação, o homem pedia um sinal divino de permissão ou negação. Essa cultura da sociedade grega impedia, por medo dos Deuses, uma atitude desrespeitosa com o ambiente.

A natureza sempre despertou no homem

[...] um olhar de curiosidade para os mais diversos fenômenos naturais como os raios e trovões, o vento, as estrelas, a lua, os tremores de terra, o movimento do mar, as estações do ano, os diversos tipos de animais e plantas, por exemplo. Entretanto, mesmo diante de toda a busca pelo convívio com tais fenômenos, o homem sempre esteve vulnerável às intempéries variadas, buscando associar suas necessidades às condições naturais, e com isso, a relação entre seres humanos e o ambiente natural desenvolveu-se de acordo com o aprimoramento de mecanismos básicos que os permitissem saciar suas necessidades primordiais. Mas, tal modo de convivência mostrou-se insuficiente diante da ânsia humana de compreender os fenômenos naturais, o que promoveu grandes alterações no modelo de relação ser humano-natureza existente até então (SANTOS, 2013, p. 3).

Os gregos passaram a tentar explicar o Cosmos por meio de observação e raciocínio e progressivamente a natureza passou a ser explicada em suas caraterísticas próprias e não mais mitológicas (SANTOS, 2013).

Com o passar do tempo a cultura mudou, e o homem com sua evolução do pensamento passou a se distanciar dos deuses cada vez mais, e a se colocar no centro, e se distanciar da natureza por efeito das convicções da ciência no período da modernidade. A modernidade é um período cujos limites de início e fim são grandes acontecimentos na história após o período medieval. É o rompimento com a tradição em função da razão, e com Deus em função da subjetividade, pois sai de uma visão teocêntrica para uma visão antropocêntrica. A modernidade objetiva o esclarecimento e a emancipação e sua Teoria do Conhecimento e se fundamenta em dois elementos constitutivos a razão e a subjetividade.

O pensamento moderno é a compreensão racional da natureza, amplamente expandida nos séculos $\mathrm{XV}$ e XVI, originando um ser humano autônomo, racional, consciente e confiante para compreender a natureza, livre dos mitos e não mais tão crente dos dogmas religiosos. O pensamento moderno traz três formas diferentes e relacionadas de pensar: 1) o Renascimento; 2) a Reforma; e 3) a Revolução Científica. Essa transformação ocorrida na era Moderna faz surgir a ciência como uma a nova crença do Ocidente (SANTOS, 2013).

O Renascimento (entre os séculos XV e XVI) provoca transformações na literatura, filosofia, artes e ciência. A mentalidade do homem muda, pois passa a tomar consciência de suas capacidades, se orientando por suas próprias ações. Esse período foi marcado por um movimento cultural de transição das tradições medievais para um mundo novo, inspirado na (antiguidade) cultural greco-romana e culminando na ruptura com o fanatismo religioso, se afastando de Deus e colocando o homem no centro. O homem toma consciência de suas capacidades e coloca em questão os dogmas religiosos. "O homem descobre que é capaz de decidir por si, buscando objetividade nas suas experiências, o mundo deixa de ser sagrado para tornar-se num objeto de uso para o próprio homem, embora a crença em Deus permanecesse" (PRIMON et al, 2000, p. 36). Os dogmas e as verdades são revistos, inclusive a autoridade religiosa do Papa é contestada por Lutero originando o Protestantismo e a reforma da igreja. Esse movimento evidenciou a razão humana e isso representou a libertação da ignorância e dos abusos praticados pela igreja e autoridades da época, dando origem ao que chamamos de modernidade.

Todos esses acontecimentos também influenciaram o surgimento da ciência moderna criada por Galileu. A concepção de natureza se alterou, rompendo com a concepção de mundo incontestada por séculos (ALMEIDA, 2004). O pensamento científico passou a ser a nova forma de adquirir conhecimento, visto que a capacidade do homem em compreender o mundo aumentou mudando as velhas concepções sobre a teoria geocêntrica e o universo, assim como, a relação do homem com a natureza (SANTOS, 2013). 
Segundo Lander (2005, p. 9), as separações ou partições do mundo real se dão concretamente com o desenvolvimento das ciências modernas, pois ocorre a "ruptura ontológica entre corpo e mente, entre razão e o mundo", ou seja, a partir desse momento o mundo está morto porque já não tem uma ordem significativa. O homem não se encontra mais em sintonia com o cosmos como na antiguidade, para o homem moderno, por meio da razão, o mundo passa ser entendido através de conceitos mecânicos, pois este é entendido como um mecanismo em Descartes. Quem inicia esse processo de separação é Kant quando fala em natureza interior e exterior. "Para ele a natureza interior dos seres humanos compreendia suas paixões cruas, enquanto a natureza exterior era o ambiente social e físico no qual os seres humanos viviam" (OLIVEIRA, 2002, p. 1-2).

De acordo com Oliveira (2002), existe uma dupla concepção de natureza: a exterior que é natureza a primitiva, a matéria-prima utilizada pelo homem e criada por Deus e a natureza interior, concebida como universal, a natureza humana, aquela que contém o fato dos seres humanos e seu comportamento serem naturais assim como aquilo que está externo à natureza. Já Francis Bacon compreendia a natureza como exterior à sociedade, pois a relação entre elas era mecânica onde o homem exercia o domínio da natureza pela mecânica de Descartes. A ideia de Bacon só não era considerada arbitraria porque ele já vivenciava a conexão entre indústria e ciência, onde a mecânica já estava a serviço da produção para aumentar a produtividade por meio do trabalho (OLIVEIRA, 2002).

A ciência passa a ser prestigiada pela cultura moderna, pois surge como possibilidade de certeza racional e oferece por meio de experimentos previsões e controle da natureza. O Universo passa a ser entendido por meio de investigação científica, tratando-se "do domínio intelectual sobre a natureza e da busca constante de aperfeiçoamento material" (SANTOS, 2013, p. 5).

A ciência foi considerada a salvadora da cultura moderna, oferecendo novas possibilidades da certeza racional, novos experimentos e previsões, muita criatividade e encorajamento para o desenvolvimento de técnicas de controle da natureza. A partir daí, conhecer "passava a ser uma questão de investigação científica, constituída de modo impessoal e realista, tratava-se do domínio intelectual sobre a natureza e da busca constante de aperfeiçoamento material” (SANTOS, 2013, p. 5).

As ideias do movimento humanista se tornaram o espírito do Renascimento gerando um grande avanço nas áreas das artes, literatura e ciências. Com o desenvolvimento da ciência moderna se deu o desenvolvimento de vários instrumentos como bússola, astrolábio e sextante que foram importantes na expansão marítima que era necessária visto que árabes detinham o monopólio sobre os produtos orientais.

O Século XVIII foi considerado o século das luzes, a iluminação racional. O lluminismo (movimento cultural filosófico) criticou o modelo de sociedade medieval instaurando um mundo moderno. Segundo Pontel e Mass (2013, p. 60)

O Iluminismo emerge na sociedade europeia, fragmentada nas diversas dimensões, em resposta ao antigo sistema, que entra em crise, e que, por consequência, aspira a uma reorganização social, uma reestruturação da sociedade. $O$ foco desta reestruturação parece estar centrado em superar tudo aquilo que limitasse o direito da livre personalidade individual, na defesa dos ideais liberais que despontavam no século XVIII.

O homem toma consciência de suas capacidades e coloca em questão os dogmas religiosos. Esse movimento evidenciou a razão humana e isso representou a libertação da ignorância e dos abusos praticados pela igreja e autoridades da época.

A modernidade é um período cujos limites de início e fim são grandes acontecimentos na história após o período medieval. É o rompimento com a tradição, em função da razão, e com Deus em função da subjetividade, pois sai de uma visão teocêntrica para uma visão antropocêntrica.

Esta foi uma época de muita criatividade e criações e nessa atmosfera ocorre a Revolução Científica e uma nova forma de conhecer e compreender o mundo o que culmina na Revolução Industrial. Com o desenvolvimento das ciências constrói-se a ideia de crescimento, de desenvolvimento. Com o desenvolvimento, se altera mais ainda a relação do homem com a natureza para sustentar o capitalismo. $O$ 
pensamento moderno tinha o objetivo de esclarecer e emancipar sua Teoria do Conhecimento a partir da razão e da subjetividade.

Acreditava-se na razão e no poder da ciência como resposta para todos os problemas da humanidade, que a partir dela teríamos uma "era marcada pela saberia, pela paz, prosperidade material e domínio humano sobre a natureza" (SANTOS, 2013, p. 5).

Acreditava-se que o triunfo da razão e da ciência sobre o transcendente sanaria os males sociais, a ignorância e o sofrimento humano. [...] Entretanto, no decorrer do século $\mathrm{XX}$, quando as consequências práticas do conhecimento científico já não poderiam ser exclusivamente consideradas favoráveis, o ser humano viu-se obrigado a reavaliar suas crenças na supremacia da razão (SANTOS, 2013, p. 6).

A ciência teve seu apogeu no século XIX e início do século XX, com muitos avanços e sua aplicação prática na vida diária das pessoas por meio da tecnologia, mas é também no século XX que as consequências negativas apareceram afetando a qualidade de vida do ser humano, sendo chamados de problemas socioambientais, havendo necessidade de reavaliar as crenças da razão. A crítica foi feita por ambientalistas de forma ampla e severa em relação ao uso indiscriminado da tecnologia e ao processo de desumanização do homem, pois este se distanciava cada vez mais da natureza em busca de uma vida superficial, surgindo os problemas de poluição e efeitos nocivos à vida vegetal e animal - incluindo o homem - extinção de espécies, devastação de florestas, acúmulo de lixo entre outros incontáveis problemas derivados do capitalismo que visa o lucro a qualquer preço (SANTOS, 2013).

Houve uma crítica severa a respeito do uso indiscriminado da ciência e tecnologia na exploração do ambiente assim como aos efeitos dessa exploração na natureza, culminando em vários impactos ambientais.

No decorrer dos séculos, o projeto de emancipação Moderna foi questionado e criticado. 0 caminho que a humanidade trilhou, principalmente em relação aos direitos humanos, levou à crise da modernidade fazendo-se repensar alguns paradigmas entre eles a cultura.

\section{O Século XVI marca o nascimento do Brasil influenciado pelas ideias dos Jesuítas e da modernidade}

Em primeiro momento o principal objetivo de Portugal sobre o Brasil era de exploração com objetivo de garantir os lucros. Somente trinta anos depois da invasão o Governo de Portugal iniciou a colonização. Em função do fracasso das capitanias hereditárias, escassez de pau brasil, escassez de ouro e pedras preciosas, o perigo de perder território para a França e a não submissão dos indígenas ao trabalho escravo, o governo de Portugal resolveu agilizar o processo de colonização (ALVES, 2009).

Para atender o mercado externo, as colônias cultivavam cana-de açúcar em larga escala com uso de mão-de-obra escrava indígena (ALVES, 2009). Como os indígenas não aceitavam trabalhar para os colonos e frequentemente atacavam os povoados, houve a necessidade de "domá-los" para exercer o trabalho na lavoura e em outros setores. Para "domá-los", perceberam a necessidade de descaracterizar, destruir suas crenças e deuses por meio da cristianização e assim em 1549, o primeiro grupo de jesuítas chegou ao Brasil, chefiados pelo Padre Manoel da Nóbrega, com a intensão de escolarizar os indígenas.

A escola para os índios tinha três objetivos básicos: 1) converter os nativos à fé Cristã; que acabou por contribuir com os objetivos da Coroa Portuguesa que eram 2) formar mão-de-obra; e em consequência 3) Incorporar os índios à nação como trabalhadores nacionais, desprovidos de atributos étnicos e culturais, abandonando sua identidade (BRASIL, 2007b).

Em 1556, o padre Nóbrega implantou o sistema de aldeamento, com intensão de melhorar a cristianização que ainda não tinha êxito entre os indígenas. Nos aldeamentos os padres eram rígidos e aplicavam disciplinamento militar para manter a ordem, a obediência e o esquecimento dos antigos hábitos dos indígenas (BORTOLOTI, 2003). Nas aldeias moravam os índios que seriam convertidos e os 
padres jesuítas que tinham objetivos doutrinários, econômico e político. O doutrinário visava ensinar a religião e a prática cristã, o econômico visava ensinar o hábito do trabalho, e o político visava usar os índios convertidos contra os índios selvagens quando atacavam as aldeias e inimigos externos.

Os missionários fizeram uma adaptação de várias línguas faladas pelos indígenas, transformando em uma língua geral e única, que era ensinada aos indígenas de várias comunidades diferentes que viviam nos aldeamentos. Os índios cristãos eram obrigados a aprender essa nova língua servindo como tradutores para jesuítas facilitando o aprendizado da língua portuguesa. Na verdade a opressão imposta pelos jesuítas objetivava não a educação em si, mas uma forma de adaptá-los mais rapidamente à dominação para a construção de uma "sociedade justa e organizada", na visão dos jesuítas é claro, e para que isso ocorresse, a mentalidade do índio deveria ser ajustada, adestrada, começando pela aprendizagem da língua portuguesa.

Os mitos e histórias narradas pelos indígenas, foram aproximados às histórias da cristandade pelos jesuítas sendo utilizadas na catequese e aproximando as duas culturas. Os jesuítas desenvolveram várias estratégias pedagógicas para cristianizar os indígenas nos aldeamentos, entre elas a música, pois perceberam o efeito que a música exercia sobre os eles. Introduziram a música através dos meninos órfãos e elaboraram um repertório de composições que falavam do Deus cristão e adaptaram ao estilo indígena, inclusive usando seus instrumentos. Pode-se dizer que a música foi um instrumento de aculturação. Além da música, o teatro também foi utilizado como instrumento de conversão religiosa e formação moral, educacional e entretenimento. O teatro era apresentado em tupi e em português porque visava atingir não só os indígenas, mas também os colonos, contrariando o Ratio Studiorium que determinava que as encenações fossem em latim. Assim sucederam as adaptações, cantos, danças e músicas que só foram toleradas porque tinham o objetivo de prender a atenção dos indígenas, ensinar a fé cristã e integrá-los à sociedade europeia, renunciando seu modo de viver (BORTOLOTI, 2003).

No século XX o aldeamento era uma ferramenta primordial para atingir os objetivos de catequização e civilização. A educação indígena passa a ser vista como fundamental para a sobrevivência física do índio no que tange não apenas a leitura e a escrita, mas também a ensinamentos como higiene, saneamento, estudos sociais, aritmética, ensinos práticos e técnicas agrícolas, marcenaria, mecânica e costura, isso tudo para formar produtores de bens de interesse comercial por meio de mão de obra barata, abastecendo o mercado regional além de servirem como consumidores de produtos produzidos pelos não indígenas (BRASIL, 2007b).

Ainda no Século XX, o governo organiza uma política indigenista para mudar a imagem do País perante a sociedade nacional e internacional. Foram criados órgãos governamentais com as seguintes funções: prestar assistência aos índios protegê-los contra exploração e opressão, e intermediar as relações entre índios, não-índios e órgãos do governo. Com essa intenção, em 1910, foi criado o Serviço de Proteção aos Índios (SPI) e extinto em 1967, repassando suas funções à Fundação Nacional do Índio (FUNAI). Entre as responsabilidades dos órgãos indigenistas está a educação escolar que segundo Brasil (2007b, p. 13) "assume papel fundamental no projeto republicano de integração do índio à sociedade nacional por meio do trabalho".

Segundo Collet (2003), o Brasil enfrentava problemas com a educação para índios e implantação do bilinguismo, pois havia 66 escolas em áreas indígenas que seguiam o padrão da escola rural, alfabetizando apenas em português, e com esse modelo não foi possível a alfabetização das populações indígenas. A missão evangélica americana, Sammer Institute of Linguistics (SIL) que atuou em vários países da América com projetos voltados para educação bilíngue, se propôs a atuar em conjunto com o Serviço de Proteção ao Índio (SPI), que não aceitou a proposta, pois além de acreditar num indigenismo independente de organizações missionárias criticava o SIL por colocar seus serviços em função da integração civilizatória e cristianizante.

Dessa forma, o SIL procurou a ajuda e assinou um convênio com o Museu Nacional, em 1957 sendo aceito para fazer uma pesquisa linguística, em relação a registro, identificação de sistemas de sons, elaboração de alfabetos e estrutura gramatical com os povos indígenas no Brasil. Mas não foi exatamente isso que aconteceu, o SIL desenvolveu muitos materiais didáticos enquanto poucas línguas foram analisadas e para piorar a situação, o SIL conseguiu assinar outro convênio com a FUNAI que lhe passou 
a responsabilidade pelo seu setor educacional, fazendo da escola um lugar de conversão religiosa e cultural.

Quando a educação escolar indígena foi assumida pelo Ministério da Educação, se deu a ruptura com o SIL, mas sem alterações metodológicas, pois ainda se praticava a mesma educação dos períodos colonial e imperial, cujo objetivo era integrar os povos indígenas à sociedade nacional por meio da adaptação a uma nova língua, nova religião ${ }^{3}$, novas crenças, novos costumes e tradições que lhes foram impostos, ou seja, para serem brasileiros, tinham que abandonar sua própria identidade (BRASIL, 2007b).

Freire (2004 p. 24) ainda enfatiza que a escola foi, para esses povos, "durante cinco séculos, um instrumento de opressão, o que está registrado atualmente na memória oral de muitos povos e foi até mesmo incorporado em alguns de seus mitos".

Baseado nessas outras pedagogias grupos da sociedade civil se organizaram para trabalhar com as minorias, entre eles os indígenas, na busca de alternativas e formas menos violentas de relacionamento entre as duas sociedades, a indígena e não indígena (BRASIL, 1999a). A escola para indígenas passou a ter um novo sentido, pois a partir desse momento buscava-se uma escola sem negar a identidade e as especificidades culturais desses sujeitos.

A Constituição Brasileira de 05 de outubro de 1988 (BRASIL, 1988), no capítulo VIII, título VIII, restitui o índio à sua condição original de primeiro cidadão do Brasil, e legítimo dono da terra entre outros direitos que são reforçados na Lei de Diretrizes e Bases da Educação Nacional (Lei $n^{\circ}$ 9394/06) em seu artigo 78:

O Sistema de Ensino da União, com a colaboração das agências federais de fomento à cultura e de assistência aos índios, desenvolverá programas integrantes de ensino e pesquisa, para a oferta de educação escolar bilíngue intercultural aos povos indígenas com os seguintes objetivos: I) proporcionar aos índios, suas comunidades e povos, a recuperação de suas memórias históricas; a reafirmação de suas identidades étnicas; a valorização de suas línguas e ciências; II) garantir aos índios, suas comunidades e povos, o acesso às informações, conhecimentos técnicos e científicos da sociedade nacional e demais sociedades indígenas e não-índias (BRASIL, 1996).

Os direitos reconhecidos aos índios representam na verdade uma forma de remissão da nação brasileira por todo o sangue derramado durante o período de colonização, pelos maus tratos, pela escravidão, pela imposição e principalmente pela falta de entendimento dos portugueses que se julgavam superiores, mas que na verdade por tamanha ignorância não souberam enxergar, valorizar e aprender todo conhecimento indígena sobre a terra conquistada.

\section{REFLEXÕES}

\section{A Cultura Indígena e as Interferências Interculturalizantes}

Antes da colonização, os indígenas eram povos coletores, retirando da natureza apenas o necessário para sua subsistência, mas após o contato esses povos tiveram que se adequar às novas condições de vida (MUSSI et al, 2010). Hoje o contato desses com a sociedade envolvente é muito forte devido à proximidade com a zona urbana, ocorrendo a hibridização da cultura e a partir disso, conforme afirma Hall (2003, p. 133), transformam e ressignificam seus costumes e práticas.

[...] elementos novos e velhos são reagrupados ao redor de uma nova gama de premissas e temas. Mudanças em uma problemática transformam significativamente a natureza das questões propostas, as formas como são propostas e maneira como podem ser adequadamente respondidas. Tais mudanças de perspectivas refletem não só os resultados do próprio trabalho

\footnotetext{
3 Juntamente com o SIL atuaram mais de 50 missões católicas e protestantes (CADERNOS SECAD/MEC V. 3, 1997).
} 
intelectual, mas também a maneira como os desenvolvimentos e suas verdadeiras transformações históricas são apropriados no pensamento e fornecem ao Pensamento, não sua garantia de correção, mas suas origens fundamentais, suas condições de existência.

Quando sociedades diferentes passam a conviver, ocorrem trocas de conhecimentos e em ambos os lados há aquisição de novos conhecimentos com ressignificações, se tornando híbridos. Inspirado em Hall (2003), pode-se dizer que os indígenas, por conta dos acontecimentos no decorrer da história, se apropriaram de tais mudanças no pensamento de acordo com suas condições de existência. Um exemplo disso é o que ocorre com a etnia terena que segundo Farias e Medeiros (2017, p. 59-60)

[...] são um povo que luta constantemente para manter viva a sua cultura, embora com influências de costumes não indígenas presentes nas comunidades e no entorno e estão sempre fazendo os rituais da dança tradicional Terena, como a dança do bate-pau, apresentada por homens ou crianças do sexo masculino, e também mantendo o jeito de ser Terena no seu cotidiano, como a valorização da oralidade e a continuidade dos ensinamentos da prática cultural indígena

Ao contrário do que o projeto moderno desejava, "as culturas tradicionais colonizadas permanecem distintas: mas elas inevitavelmente se tornaram recrutas da modernidade" (HALL, 2003, p. 72). Ao invés de homogênias, como objetivava a globalização, elas se tornaram híbridas, no sentido de mistas e diaspóricas culturalmente, possuem uma diversidade de conhecimentos diferentes em relações sustentáveis prejudicar sua autonomia (SANTOS, 2007).

Oliveira (1999, p. 169) enfatiza que "[...] as unidades sociais abondanam velhas formas culturais, recebem (e reelaboram) algumas de outras sociedades e ainda criam novas formas distintas", afinal a cultura que é dinâmica se transforma de acordo com a interação entre os grupos sociais e o ambiente em que vivem. Essa ressignificação é evidenciada na fala do professor Seizer da Silva ${ }^{4}$ (2016, p.15) quando explica esse processo em sua etnia na sua tese de doutorado:

Terena reelabora, ressignifica, apropria e incorpora, nos dando o entendimento que a etnia em si é única, mas as características produzidas e atravessadas por outras relações, produz os povos Terena, ou seja, há um fio centralizador ancestre que fortalece a teia étnica que nos liga, mais como no tecer das artesãs, cada qual coloca as cores e as formas que se deseja e/ou são necessárias, assim se produz atualmente os povos Terena [...]

A proximidade das aldeias com as cidades facilita as trocas culturais influenciando dois lados, mas segundo Freire (1983, p. 27) o conquistador utiliza "a propaganda, os slogans, os depósitos, os mitos" para manipular o conquistado a não resistir à conquista e por isso é necessária a descaracterização da cultura do conquistado, desmontando seu perfil e preenchendo-o com novas histórias e outros significados da cultura do conquistador.

Com relação a questão ambiental essa imposição cultural trazida pela globalização trouxe às comunidades indígenas vários costumes alheios à sua cultura, que com o passar do tempo também trouxe problemas socioambientais como lixo, doenças, desaparecimento de nascentes e corpos d'água entre outros, todos ligados ao problema de território mesmo tendo uma forte relação com o ambiente em que vivem.

Para analisar tais questões fazem-se necessário conhecer o meio, os valores sociais, a forma de produção e sobrevivência, as relações, as histórias de vida, ou seja, a cultura, que segundo Hall (2003, p. 136) é "o estudo entre elementos em um modo de vida global. Está perpassada por todas as práticas sociais e constitui a soma do inter-relacionamento das mesmas".

As práticas tradicionais pertencem a grupos diferenciados culturalmente, socialmente $\mathrm{e}$ economicamente que mantêm relações específicas com o território e o meio ambiente em que vivem

\footnotetext{
${ }^{4}$ Antônio Carlos Seizer da Silva é um intelectual indígena da etnia Terena do Estado de Mato Grosso do Sul.
} 
mantendo sua sustentabilidade. Segundo o Decreto 6.040, de 7 de fevereiro de 2007, que institui a Política Nacional de Desenvolvimento Sustentável dos Povos e Comunidades Tradicionais, em seu artigo 3, Inciso I, são:

Povos e Comunidades Tradicionais: grupos culturalmente diferenciados e que se reconhecem como tais, que possuem formas próprias de organização social, que ocupam e usam territórios e recursos naturais como condição para sua reprodução cultural, social, religiosa, ancestral e econômica, utilizando conhecimentos, inovações e práticas gerados e transmitidos pela tradição (BRASIL, 2007a).

Comunidades tradicionais utilizam seu território e recursos naturais de maneira própria, um jeito de fazer e viver diferente da sociedade ocidental que produzem conhecimentos que são gerados e transmitidos pela tradição, dentre essas comunidades estão as indígenas.

Para [as] populações indígenas, as atividades produtivas são basicamente para subsistência. Assim, apresentam forte dependência em relação à natureza e aos recursos naturais renováveis, os quais são os mantenedores de seu modo particular de vida. Culturalmente, a natureza representa para os indígenas muito mais do que um meio de subsistência. Representa o suporte da vida social e está diretamente ligada aos sistemas de crenças e conhecimentos, além de uma relação histórica (SOUZA, et al, 2015, p. 88)

Cada povo ou comunidade tem sua forma particular de pensar e compreender a natureza e suas relações, pois isso depende de cada cultura. Para os indígenas, as relações entre os seres vivos mais os aspectos físicos do meio e os espíritos, compõem o mundo natural ou a natureza. "Ou seja, não se constitui uma relação de exploração do homem com o ambiente, como ocorre nos moldes capitalistas, mas, sim, de reciprocidade, uma relação de dualidade entre corpo e alma, corpo e espírito (DIOCESE, 2000), uma relação social"' (SOUZA, et al, 2015, p. 89).

A lógica de exploração do ambiente advém da sociedade moderna, diferentemente das comunidades tradicionais que têm a natureza como uma extensão do seu corpo e alma e portando, a relação de troca de subsistência e, portanto, de respeito para com a natureza. Sobre essa exploração do meio ambiente pela sociedade capitalista, Kopenawa e Albert (2015, p. 74) alertam que:

Foi [Omama] que nos deu a conhecer as bananas, a mandioca e todo o alimento de nossas roças, bem como todos os frutos das árvores da floresta. Por isso queremos proteger a terra em que vivemos. Omama a criou e deu a nós para que vivêssemos nela. Mas os brancos se empenham em devastá-la, e, se não a defendermos, morreremos com ela.

As comunidades tradicionais possuem o entendimento de que a vida depende da natureza e seus conhecimentos, segundo Léve Strauss (2012) são profundos e complexos dotados de grande potencialidade. Segundo Rodrigues e Santos (2014) a Organização Mundial da Propriedade Intelectual (WIPO) em 1999 definiu conhecimentos tradicionais como conhecimentos antigos ${ }^{5}$, que ainda hoje são praticados e desenvolvidos como, por exemplo, o folclore, a medicina tradicional, técnicas de extração de recursos naturais, conhecimentos pertencentes a comunidades que os conservam passando oralmente de geração em geração.

Para Diegues (2000, p. 30) esse conhecimento é

[...] o saber e o saber fazer, a respeito do mundo natural e sobrenatural, gerados no âmbito da sociedade não urbano/industrial e transmitidos oralmente de geração em geração. Para muitas dessas sociedades, sobretudo as indígenas, existe uma interligação orgânica entre o mundo natural, o sobrenatural e a

${ }^{5}$ Antigo no sentido de existente há milhares de anos e não referente a velho ou ultrapassado. 
organização social. Nesse sentido, para estas últimas, não existe uma classificação dualista, uma linha divisória rígida entre o natural e o social, mas sim um continuum entre ambos.

Embora as definições apresentadas se aproximem, a de Diegues é mais completa, pois relaciona o natural, o sobrenatural e o social não como coisas separadas, mas como algo contínuo, ligado. O modo de ser, viver e fazer das populações indígenas apresentam grande conexão e dependência da natureza e seus recursos naturais.

Essa conexão e dependência da natureza e dos recursos aparece na fala de Gersem Baniwa quando explica o que os sábios indígenas dizem aos seus jovens a respeito dos deuses e espíritos dos mitos:

É muito comum os sábios indígenas, ao serem perguntados por jovens sobre os espíritos, os deuses e outros seres sobrenaturais que existiam segundo os mitos, responderem que foram destruídos juntos com a natureza. Em outras palavras, os deuses indígenas não existem sem a natureza real e concreta. Assim, os índios nunca buscam controlar e dominar a natureza, mas tão-somente compreendêla, para que se sirvam dela com respeito para tirar o seu sustento e a cura para as doenças consideradas como o resultado da transgressão das leis da natureza e da vida. Para as comunidades indígenas, a natureza não é um recurso manipulável, mas um habitat, uma casa, um lugar em que se está e onde se vive. Para os índios, o território é um lugar sagrado, no sentido de que ele é o próprio gerador da vida. (LUCIANO, 2006, p.103)

Esses povos ou sociedades tradicionais são considerados culturalmente, socialmente $\mathrm{e}$ economicamente diferenciados. Eles mantêm relações com o meio ambiente respeitando o princípio de sustentabilidade assegurando as mesmas possibilidades para as gerações futuras (MINAS GERAIS, 2014). Seus saberes são coletivos e diversos cada sociedade tem o seu, mesmo aquelas que estão em contato mais próximo com a sociedade envolvente ainda guardam fortes vínculos com a natureza.

Krenak (2018, s/p) enfatiza esse vínculo afirmando que:

Cada igarapé tem um nome, e esse nome é invocação de outros seres, dos seus parentescos, das narrativas mais antigas que chegam em nossa memória. Isso que dá sentido para chamar a terra de mãe [...]. Por mais que eles tentem transformar em estoque fundiário, tirar o sentido de vida que a terra tem, essa gente que nasceu na terra, e tem a memória da terra não aceita isso. Esperneia, morre, continua reaparecendo em outros termos, mas continua lutando e berrando, dizendo que aquilo é a mãe terra. [...]

Krenak se considera um exilado de sua terra, o Rio Doce. A colonização expulsou os indígenas daquele lugar, e ele explica que mesmo não podendo mais habitar seu local de origem, as narrativas mais antigas ainda o acompanham. Narrativas sobre a natureza e sobre a terra que sustenta os seres e por isso "mãe terra".

Para entender essa compreensão essa ligação com a terra (lugar), Tristão (2004) aponta, que é necessário compreender que cultura e meio ambiente não se encontram separados, a cultura é natureza assim como natureza é cultura. Os seres humanos se organizam em sociedade e mantém relações com o meio em que vive assim cada grupo constrói sua ideia de natureza relacionando com sua cultura. A noção de natureza depende da cultura em que ela está inserida, como hábitos, costumes e valores próprios daquele lugar. O lugar "continua sendo importante na vida da maioria das pessoas, talvez para todas. Existe um sentimento de pertencimento que [é] mais importante do que queremos admitir [...]" (ESCOBAR, 2005, p. 63).

Escobar (2005, p. 63) ainda alerta que nos últimos anos com a euforia da globalização, houve um enfraquecimento da ideia de lugar, impactando negativamente na compreensão da cultura, do conhecimento, da economia, da natureza e que talvez agora seja o momento de reverter, fortalecer a importância do lugar e da "criação do lugar, para a cultura, a natureza e a economia da perspectiva de lugar oferecida pelos próprios críticos". 
Com o desenvolvimento na Modernidade e da ciência, houve um rompimento, para as pessoas, do lugar. No entendimento de Krenak (2018, s/p) "qualquer um no seu lugar de origem está totalmente encaixado, [...]. Mas quando ele é arrancado desse lugar e jogado num outro ponto qualquer, ele tem que se realocar. Esse desterrado agora vai ter que reinventar ele e seu mundo". Mesmo em um lugar diferente de sua origem, a cultura, religião e crenças não mudam, o que ocorre é uma adaptação ao novo ambiente.

Por esse motivo, "as teorias do pós-desenvolvimento e a ecologia são espaços de esperança para reintroduzir uma dimensão baseada no lugar, nas discussões sobre a globalização, talvez até para articular uma defesa do lugar" (ESCOBAR, 2005, p. 63). Portanto, o fortalecimento do lugar, a discussão sobre a cultura local contrária ao domínio de espaço, a modernidade e o capital, temas do discurso de globalização, podem visibilizar possibilidades de reconstruir espaços a partir de práticas fundamentadas no lugar (ESCOBAR, 2005).

A etnobotânica, a etnociência e a antropologia ecológica muito se desenvolveram baseadas nas pesquisas sobre o conhecimento local, do lugar, e os modelos culturais de natureza (ESCOBAR, 2005). Nas comunidades tradicionais indígenas, "as plantas, os animais e outras entidades pertencem a uma comunidade socioeconômica, submetida às mesmas regras que os humanos" (ESCOBAR, 2005, p. 65). Aos seres vivos, não vivos e supranaturais não constituem domínios distintos ou separados, as relações sociais abrangem mais que aos seres humanos apenas. "Vivemos num mundo que não está separado de nós, e nosso conhecimento do mundo pode ser descrito como um processo de adestramento no contexto do envolver-se com o meio ambiente" (ESCOBAR, 2005, p. 66).

Conforme os registros bibliográficos nos indicam, os indígenas sempre tiveram em sua gênese, essa relação de continuidade com o meio ambiente, eles se sentiam parte do meio e não como algo separado ou superior, tal sentimento de pertencimento sempre esteve presente em sua cultura e seus rituais.

\section{A Ecologia de Saberes das Comunidades Tradicionais e a Educação Ambiental}

Há uma diversidade de conhecimentos, saberes, de epistemologias nas relações entre os seres humanos e natureza. As sociedades da natureza percebem os lugares como ambientes produtores de ensinamentos de pensar e estar no mundo (TRISTÃO, 2016). As palavras de Tristão são corroboradas por Kopenawa e Albert (2015, p.75)

Nossos pensamentos se expandem em todas as direções e nossas palavras são antigas e muitas. Elas vêm de nossos antepassados. Porém, não precisamos, como os brancos, de peles de imagens para impedi-las de fugir da nossa mente. Não temos de desenhá-las, como eles fazem com as suas. Nem por isso elas irão desaparecer, pois ficam gravadas dentro de nós.

Kopenawa explica que os indígenas não precisam de papel para deixar registrado seus conhecimentos como os não indígenas, mas que seus conhecimentos são herdados dos seus antepassados e ficam registrados em sua memória. Ele ainda continua explicando que seus saberes advêm dos espíritos que o acompanham que estão dentro de si.

A imagem de Omama disse a nossos antepassados: "Vocês viverão nesta floresta que criei. Comam os frutos de suas árvores e cacem seus animais. Abram roças para plantar bananeiras, mandioca e cana-de-açúcar. Deem grandes festas reahu! Convidem uns aos outros, de diferentes casas, cantem e ofereçam muito alimento aos seus convidados!”. Não disse a eles: “Abandonem a floresta e entreguem-na aos brancos para que a desmatem, escavem seu solo e sujem seus rios!”. Por isso quero mandar minhas palavras para longe. Elas vêm dos espíritos que me acompanham, não são imitações de peles de imagens que olhei. Estão bem fundo em mim (KOPENAWA; ALBERT, 2015, p. 76).

Os saberes tradicionais indígenas além de vir dos antepassados que ficam registrados em sua memória, advêm também dos espíritos que os acompanham que estão dentro de si. 
O professor Seizer da Silva (2016, p. 19), da etnia Terena, ratifica essa ideia ao dizer: "Reinventamosnos, estabelecemos novas conexões com outros saberes, nos tornamos Terena com memória cosmológica "cristalizada" nos saberes dos meus avós maternos".

O reconhecimento desses outros saberes, Santos (2008) chama de ecologia de saberes e a compreende como um conjunto de epistemologias da diversidade, a prática de saberes.

A ecologia de saberes procura dar consistência epistemológica ao saber propositivo. Trata-se de uma ecologia porque assenta no reconhecimento da pluralidade de saberes heterogêneos, da autonomia de cada um deles e da articulação sistêmica, dinâmica e horizontal entre eles. A ecologia de saberes assenta na interdependência complexa entre os diferentes saberes que constituem o sistema aberto do conhecimento em processo constante da criação e renovação. O conhecimento é interconhecimento, é reconhecimento, é auto-conhecimento (SANTOS, 2008, p. 157)

A ecologia dos saberes se situa em um contexto cultural ambíguo, porque enquanto o reconhecimento da diversidade sociocultural favorece o reconhecimento da diversidade epistemológica de saber no mundo, todas as epistemologias também partilham as premissas culturais do seu tempo, sendo a crença na ciência como uma forma de conhecimento válido, a mais consolidada (SANTOS, 2008). Em função disso que Tristão (2014) afirma que é importante ser flexível na interpretação do mundo dinâmico com economias integradas onde essas comunidades sofrem pressão da economia de mercado e dos impactos no ambiente de onde tiram sua subsistência.

Fundamentada nessas compreensões que a Educação Ambiental (EA) tem produzido narrativas de valorização dos saberes das comunidades tradicionais, o que na concepção de Tristão (2014) é um pouco preocupante, visto que, se corre o risco de essencializar a cultura por conta desse encantamento. A EA ao incorporar as narrativas da diversidade cultural expõe a hierarquização das culturas, principalmente das excluídas pela homogeneidade dominante da modernidade e seus processos globalizantes, mas ao mesmo tempo essa supervalorização da herança tradicional, pode defender e homogeneizar algumas culturas consideradas tradicionais ou sustentáveis conferindo a elas um sentido de pureza que não existe (TRISTÃO, 2014).

A Educação Ambiental é um processo em que os indivíduos e a sociedade se conscientizam de seu ambiente e adquirem conhecimentos, valores, experiências para que sejam capazes de agir e solucionar problemas ambientais (UNESCO, 1987). Mas a Educação Ambiental também pode ser entendida como um processo onde os indivíduos constroem valores sociais, habilidades e conhecimento para pensar a conservação ambiental para uso comum e sustentável pela população (BRASIL, 1999b).

De acordo com Brasil (1999b), um dos objetivos da Educação Ambiental (EA) é criar e ampliar formas sustentáveis de relações entre a sociedade e a natureza (socioambiental) assim como mitigar os problemas ambientais. Segundo Carvalho (2008) a visão socioambiental direciona-se para a racionalidade complexa e interdisciplinar pensando o ambiente como campo de interações entre cultura, sociedade e parte biótica e abiótica. Essa relação é dinâmica e causa modificações mútuas. Nesse caso a presença humana é vista como integrante à teia de relações da vida, interagindo no social, natural e cultural.

Para Hall (2003, p. 141-142) não é possível pensar a natureza independente da cultura, pois cultura é "algo que entrelaça todas as práticas sociais, e essas práticas, por sua vez, como uma forma comum de atividade humana: como práxis sensual humana, como a atividade através da qual homens e mulheres fazem a história". Embora Hall se refira à natureza humana, me atrevo a relacionar e pensar essa natureza como o meio ambiente, pois a relação humana com o meio ambiente depende também de sua cultura. Se a cultura é baseada nas ideias da modernidade e do capitalismo, com certeza os recursos ambientais serão explorados até o máximo que a leis permitem, mas se a cultura é baseada no pensamento de interdependência e que o ser humano faz parte dessa natureza então essa relação é sustentável.

\section{CONSIDERAÇÕES FINAIS}

Olhar para trás utilizando a história nos faz compreender o que ocorre hoje. Vimos que as sociedades gregas tinham uma relação diferente com o meio em que viviam e como isso foi se 
modificando com o passar do tempo. Mas não podemos esquecer que não há apenas uma história, ela é feita de narrativas, a dos dominantes e a dos dominados, sabendo que a história dos dominantes, a hegemônica, geralmente sobrepõe a dos dominados.

O Brasil foi invadido numa época em que na Europa fervilhava novos pensamentos. Nessa época, a ciência e a tecnologia estava em ascensão, o que fez o homem se distanciar de Deus e da natureza. $O$ Homem passou a subjugar a natureza para viver numa nova lógica, a da exploração para o sustento de um novo sistema econômico, o capitalismo. Dessa forma, o Brasil foi uma colônia de exploração, da natureza e dos povos originais. Os indígenas foram explorados, expropriados, assassinados e os poucos que sobraram foram obrigados a mudar sua forma viver.

Com o decorrer do tempo, o capitalismo trouxe consigo os impactos ambientais atingindo diretamente as sociedades humanas, gerando os problemas socioambientais. Estamos inquestionavelmente vivendo uma grave crise socioambiental, o que tem levado a humanidade a repensar a sua forma de viver. Neste sentido, a teoria pós-colonial nos faz refletir a partir do passado, as relações de poder do império sobre as colônias, inclusive também no que se refere aos aspectos ambientais.

Hoje, o mundo contemporâneo vive em um constante alerta quando o assunto é meio ambiente, pois em função do modelo de exploração do capitalismo adquirimos várias doenças relacionadas principalmente a consequente poluição resultante do modelo de produção predatório que estamos assistindo. Muitas espécies já foram extintas, o clima do planeta tem mudado e tudo isso tem afetado diretamente os ecossistemas, a cadeia alimentar e comprometendo todas as formas de vida no planeta. Dessa forma os estudiosos da Educação Ambiental fazem alertas sobre os impactos dessa cultura da exploração que se acentua em nome de um discutível "progresso" e "desenvolvimento".

Como vimos, as teorias Pós-coloniais fazem as análises das relações de poder existentes desde os tempos coloniais, reconhecem e apontam a continuidade da colonialidade por meio do discurso da ciência moderna, da razão e da cultura europeia, conferindo subalternidade às alteridades em suas subjetividades. Já os estudos culturais focam na análise da cultura e fazem a crítica às relações de poder ligadas a situações culturais, se posicionam a favor dos grupos em prejuízos nessa relação, e fazem a crítica ao enquadramento dos sujeitos à norma que segue as características ocidentais.

A Educação Ambiental inspirada na teoria Pós-Colonial, está partindo para desenvolver caminhos alternativos das relações de poder, de colonização e submissão entre culturas e nações, dando ênfase na compreensão das dimensões: lugar, cultura e narrativa. Com esse entendimento, consideramos que as comunidades indígenas possuem uma cultura com uma lógica diferente, e os Estudos Culturais nos ajuda a perceber que as narrativas contadas pelas comunidades tradicionais a partir das histórias, das lendas e mitos são valiosos, no sentido de compreender o respeito pelas relações e inter-relações de interdependência com os outros seres vivos e não vivos (físicos e espirituais).

Como constatamos nas palavras sábias dos mestres tradicionais Ailton Krenak e Davi Kopenawa, a visão de mundo e de vida dos indígenas promove a sustentabilidade em seus espaços de vivência e convivência, seus lugares de cultura.

Compreender tais relações parece ser um caminho a ser trilhado no sentido de refletir e debater soluções para os impactos ambientais herdados da Ciência Moderna.

Hoje as comunidades indígenas cresceram em número populacional e grande parte delas vivendo em territórios pequenos, dessa forma, alguns deixaram de produzir alimentos porque já não possuem espaços para suas roças, deixaram de caçar e pescar porque já não possuem mais florestas e rios, muitos vivem em outros locais que não são seus lugares de origem. Por isso tiveram que se adequar às novas situações vivenciadas se hibridizando e ressignificando suas vidas.

Muitas aldeias se localizam próximas às cidades recebendo influências da sociedade não indígena. É uma condição a que foram obrigados a viver e por isso é importante entender o contexto para entender os reflexos e impactos ambientais e sociais a que foram expostos. No meio de tanta adversidade sua 
cultura resiste e como já foi dito pelos intelectuais indígenas, estão gravadas no pensamento porque são gerados e transmitidos pela tradição de uma cultura oral que hoje também convive com registros escritos.

Acreditamos que seus saberes tradicionais, sua ciência, sua forma de compreender o mundo e se relacionar com a natureza, estão encrustadas em suas almas, e nós não indígenas devemos aprender com eles essa lógica do "Bem Viver" se quisermos que nossas futuras gerações vivam com qualidade de vida.

Assim, acreditamos que os Estudos Culturais e as teorias Pós-Coloniais em diálogo com a Educação Ambiental, nos possibilitam fazer análises outras da relação sustentável do indígena com o meio ambiente, pois acreditamos que o melhor caminho para a sobrevivência das espécies no planeta Terra, inclusive a humana, seja o de reaprender com os indígenas como viver de forma sustentável numa relação ética com a natureza

\section{REFERÊNCIAS}

ALMEIDA, Aires. Filosofia e ciências da natureza: alguns elementos históricos. Crítica. 2004. Disponível em: <https://criticanarede.com/filos_fileciencia.html> Acesso em: 19/02/2018.

ALVES, Washington Lair Urbano. A história da educação no Brasil: da descoberta à lei de Diretrizes e Bases de 1996. Monografia apresentada ao Centro Universitário Católico Salesiano Auxilium- UNISALESIANO, Lins, SP para Pós-Graduação “Lato Sensu” em Metodologia do Ensino Superior, Lins, 2009.

BANIWA, Gersem dos S. Luciano. O Índio Brasileiro: o que você precisa saber sobre os povos indígenas no Brasil de hoje. Brasília: Ministério da Educação, Secretaria de Educação Continuada, Alfabetização e Diversidade; LACED/Museu Nacional, 2006.

BORTOLOTI, Karen Fernanda da Silva. O RatioStudiorium e a missão no Brasil. Revista História Hoje, São Paulo, n 2, 2003.

BRASIL. Constituição da República federativa do Brasil de 1988. Disponível em: http://www.planalto.gov.br/ccivil_03/constituicao/constituicaocompilado.htm Acesso em: 11 nov. 2018.

BRASIL. Lei № 9.394, de 20 de dezembro de 1996. Estabelece as diretrizes e bases da educação nacional. Disponível em: <http://www.planalto.gov.br/ccivil_03/Leis/L9394.htm>. Acesso em: 11 nov. 2018.

BRASIL. Conselho Nacional de Educação. Câmara de Educação Básica. Diretrizes Curriculares Nacionais da Educação Escolar Indígena. Parecer 14/99, 1999a Disponível em: < http://portal.mec.gov.br/cne/arquivos/pdf/1999/pceb014_99.pdf> Acesso em: 11 nov. 2018.

BRASIL. Lei $N^{\circ}$ 9.795, de 27 de abril de 1999. Dispõe sobre a educação ambiental, institui a Política Nacional de Educação Ambiental e dá outras providências, 1999b Disponível em: < http://www.planalto.gov.br/ccivil_03/LEIS/L9795.htm>. Acesso em: 11 nov. 2018.

BRASIL. Decreto $N^{\circ}$ 6.040, de 7 de fevereiro de 2007. Institui a Política Nacional de Desenvolvimento Sustentável dos Povos e Comunidades Tradicionais, 2007a. Disponível em: < http://www.planalto.gov.br/ccivil_03/_Ato2007-2010/2007/Decreto/D6040.htm>. Acesso em:11 nov. 2018.

BRASIL. Ministério da Educação. Secretaria da Educação Fundamental. Cadernos SECAD 3- Educação Escolar Indígena: diversidade sociocultural indígena ressignificando a escola. Brasília: SEF/MEC, $2007 \mathrm{~b}$.

CARVALHO, Isabel Cristina de Moura. Educação ambiental: a formação do sujeito ecológico. 3. ed. São Paulo: Cortez, 2008.

COLLET, Célia Letícia Gouvêa. Interculturalidade e educação escolar indígena: um breve histórico. Cadernos de Educação Escolar Indígena. Barra do Bugres: UNEMAT, v. 2, n. 1, 2003.

DESLANDES, Suely F; GOMES, Romeu; MINAYIO, Cecília de S. (org). Pesquisa Social: Teoria, método e criatividade. 28 ed. Petrópolis, RJ: Vozes, 2009.

DIEGUES, Antônio Carlos S. Etnoconservação da natureza: enfoques alternativos. In: DIEGUES, Antônio Carlos S. Etnoconservação: novos rumos para a proteção da natureza nos trópicos. São Paulo: USP, 2000. 
ESCOBAR, Arturo. O lugar da natureza e a natureza do lugar: globalização ou pós-desenvolvimento? In: LANDER, Edgardo (org). A colonialidade do saber: eurocentrismo e ciências sociais Perspectivas latinoamericanas. Colección Sur Sur, CLACSO, Ciudad Autónoma de Buenos Aires, Argentina. setembro 2005.

FARIAS, Edineide Bernardo; MEDEIROS, Heitor Queiroz de. O Povo Terena e a Educação Escolar Indígena Diferenciada e Bilíngue em Mato Grosso do Sul. Notandum 43 jan-abr, 2017.

FREIRE, P. Extensão ou Comunicação? Trad. Rosisca D. de Oliveira. 10. ed. Rio de Janeiro, RJ: Paz e Terra, 1983.

FREIRE, José Ribamar B. Trajetórias de muitas perdas e poucos ganhos. In: FREIRE, José Ribamar B. Educação escolar indígena em Terra Brasilis, tempo de novo descobrimento. Rio de Janeiro: IBASE, 2004.

HALL, Stuart. Da diáspora: Identidades e mediações culturais. Organização Liv Sovik; Tradução Adelaine La Guardia Resende letall. Belo Horizonte: Editora UFMG; Brasília: Representação da UNESCO no Brasil, 2003.

KOPENAWA, Davi; ALBERT, Bruce. A queda do céu: Palavras de um xamã yanomami. Tradução Beatriz Perrone-Moisés; prefácio de Eduardo Viveiros de Castro. 1a ed. São Paulo: Companhia das Letras, 2015.

KRENAK, Ailton; A potência do sujeito coletivo - Parte I. Periferias. V.01, N.01, 2018. Entrevista concedida a Jailson de Souza e Silva. Disponível em: http://imja.org.br/revista/materia/a-potencia-do-sujeito-coletivoparte-i/?pdf=158 acessado em 11/11/2018.

LANDER, Edgardo. Ciências sociais: saberes coloniais e eurocêntricos In: LANDER, Edgardo (org). A colonialidade do saber: eurocentrismo e ciências sociais Perspectivas latino-americanas. Colección Sur Sur, CLACSO, Ciudad Autónoma de Buenos Aires, Argentina. setembro 2005.

LÉVI-STRAUS, Claude. O pensamento selvagem. São Paulo: Papirus, 2012.

MINAS GERAIS, Coordenadoria de Inclusão e Mobilização Sociais (CIMOS) - Ministério Público de Minas Gerais (MPMG). Direito dos Povos e Comunidades tradicionais, 2014. Disponível em: <http://conflitosambientaismg.lcc.ufmg.br/wp-content/uploads/2014/04/Cartilha-Povos-

tradicionais.pdf>. Acesso em: 25 mar. 2018

MUSSI, Vanderleia, P. L., História e Histórias dos Povos Indígenas. In: URQUIZA, Antônio H. A. (Org.) Cultura e História dos Povos Indígenas.. Universidade Federal do Mato Grosso do Sul - Coordenadoria de Educação Aberta e a Distância. Módulo 4, Marcos conceituais referentes à diversidade sóciocultural. Campo Grande - MS, 2010.

OLIVEIRA, Ana Maria Soares de. Relação Homem/Natureza no Modo de Produção Capitalista. Scripta Nova, Revista Eletrônica de Geografia y Ciencias Sociales. Universidad de Barcelona. Vo. Vl; num. 119 (18), 2002.

OLIVEIRA, João Pacheco de. Romantismo, negociação política ou aplicação da antropologia: perspectivas para as perícias sobre terras indígenas. In: OLIVEIRA, João Pacheco de. Ensaios de antropologia histórica. Rio de Janeiro: Editora da UFRJ, 1999.

PONTEL, Evandro; MASS, Olmaro Paulo. Esclarecimento e modernidade: uma leitura a partir da crítica de Adorno e Horkheimer. Revista Filosofazer. Passo Fundo, n. 42, jan./jun. 2013

PRIMON, Ana Lucia de Mônaco; JÚNIOR, Lourival Gabriel de Siqueira; ADAM, Silvia Maria; BONFIM, Tania Elena. História da ciência: da idade média à atualidade. Psicólogo informação ano 4, nº 4, jan/dez. 2000.

SANTOS, Boaventura de Souza. Para além do pensamento abissal: das linhas globais a uma ecologia de saberes. Novos Estudos - CEBRAP no. 79 São Paulo Nov. 2007.

. A gramática do tempo: para uma nova cultura política. 2. ed. São Paulo: Cortez, 2008. 
SANTOS, Janaina Roberta dos. A ciência moderna e o domínio da natureza: contribuições filosóficas para pensar a crise ambiental. VII EPEA - Encontro Pesquisa em Educação Ambiental; Rio Claro - SP, 07 a 10 de Julho de 2013.

SEIZER da Silva, Antonio Carlos. Kalivôno Hikó Trenoe: sendo criança indígena Terena do século XXI: vivendo e aprendendo nas tramas das tradições, traduções e negociações. Campo Grande; UCDB, 2016.

SOUZA, Ana Hilda Carvalho de; LIMA, Alexandrina Maria de Andrade; MELLO, Marcos Aurélio Anadem; OLIVEIRA, Elialdo Rodrigues de. A relação dos indígenas com a natureza como contribuição à sustentabilidade ambiental: uma revisão da literatura. Revista destaques acadêmicos, VOL. 7, N. 2, CCHS/UNIVATES, 2015.

TRISTÃO, Martha. A educação ambiental na formação de professores: redes de saberes. São Paulo: Annablume; Vitória: Facitec, 2004.

. A Educação Ambiental e o pós-colonialismo. Revista Educação Pública. Cuiabá, v. 23, n. 53/2, p. 473-489, maio/ago. 2014

. Educação ambiental e a descolonização do pensamento. Rev. Eletrônica Mestr. Educ. Ambient. Ed. Especial, julho/2016.

UNESCO-UNEP International strategy for action in the field of environmental education and training for the 1990s. Paris: UNESCO e Nairobi. 1987. 